\title{
Experimental and numerical investigation of the asymmetric primary creep of a fibre reinforced refractory concrete at $1200^{\circ} \mathrm{C}$
}

\author{
Gilles Dusserre $^{\mathrm{a}, *}$, Olivier Valentin ${ }^{\mathrm{b}}$, Fabien Nazaret ${ }^{\mathrm{b}}$, Thierry Cutard ${ }^{\mathrm{a}}$ \\ a Université de Toulouse, CNRS, Mines Albi, INSA, UPS, ISAE-SUPAERO, ICA (Institut Clément Ader), Campus Jarlard, F-81013 Albi, France \\ ${ }^{\mathrm{b}}$ Aurock, 54, rue Gustave Eiffel, 81000, Albi, France
}

\begin{abstract}
A B S T R A C T
Tension/compression asymmetry is a key feature of the creep behaviour of ceramics at high temperature. This paper investigates the capability of Drucker-Prager creep model, based on a sensitivity of the equivalent creep stress to the pressure, to account for the creep behaviour of a refractory concrete subjected to compression and bending. A relevant calibration procedure is proposed. The analysis mainly focuses on the associativity of the creep flow. A profile analysis of a compressed sample allows concluding that the creep flow is dilatant and thus associated. A discussion on the neutral axis shift during bending creep is carried out with the model calibrated on the experiments.
\end{abstract}

\author{
Keywords: \\ Creep \\ Concrete \\ Constitutive behaviour \\ Finite elements \\ Mechanical testing
}

\section{Introduction}

Modelling the creep behaviour is a major issue for any application involving a long-term exposure of ceramic parts to high temperature. In this framework, accounting for the well-known asymmetry of ceramics creep behaviour is a key feature, from all points of view: experimental characterization, modelling and parameter identification. The tension/compression asymmetric creep of ceramics at high temperature is generally attributed to preferential damage [1] or cavitation [2,3] in tension, or to the motion of solid particles in a glassy phase during creep deformation [4].

Asymmetric creep was evidenced from tensile and compressive tests for many materials, including ceramics [3,5]. However tensile tests on brittle materials turn out to be delicate at high temperature, whereas bending tests (which provide tensile stresses in part of the specimen) are more easily carried out. In many studies, bending was thus preferred to tension in order to assess the tensile behaviour and complete compression data $[1,6]$.

The experimental advantage of bending is counterbalanced by the complexity arising in the interpretation of the results. Indeed, a non-uniform elastic stress field is instantaneously built up and then progressively modified by the non-uniform inelastic strain

\footnotetext{
* Corresponding author.

E-mail address: Gilles.Dusserre@mines-albi.fr (G. Dusserre).
}

$[7,8]$. Primary creep still increases this non-stationary behaviour. The stress field change during asymmetric creep implies that the neutral axis in bending shifts from the specimen mid-plane [9]. The location of the neutral-axis can thus be used as an indicator of creep asymmetry [10-12]. More recently, asymmetric creep evidences were obtained from bending tests monitored by full-field measurement methods: 3D-Digital Image Correlation (3D-DIC) at room temperature after interrupted tests [13] or during the test at high temperature [14] by a global approach to 2D-DIC. Both studies have shown that the neutral axis shift mainly occurs at the beginning of the creep.

In many studies $[6,11,15-18]$ a steady-state creep law is enough to model the material behaviour. In the case of materials that exhibit a pronounced primary creep, this assumption no longer holds since the primary creep controls the stress field change. The analysis of the bending experiment is therefore much more complex. Moreover, the specimen may be subjected simultaneously to stationary creep on the upper and lower faces and to primary creep in the vicinity of the neutral axis, where the creep strain remains low. A previous work [13] has shown that the behaviour of the studied material necessitates taking the primary creep into account.

Understanding the non-uniform and non-stationary stress field involved in bending creep necessitates appropriate modelling tools. Many uniaxial creep laws exist that relate the strain rate to the applied stress. Some authors propose to explicitly account for the 


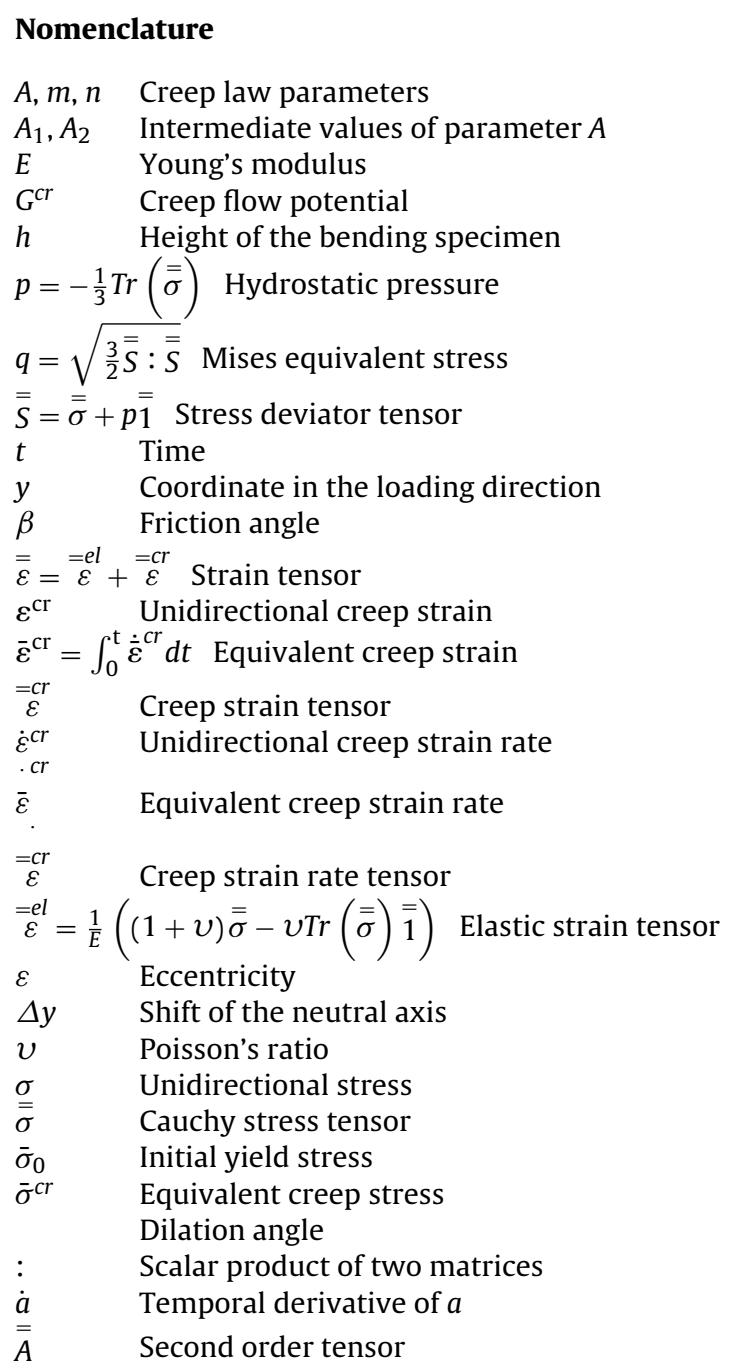

asymmetry by combining two different behaviours depending on the sign of the stress $[2,6]$.

More generally, tri-axial stress fields usually consider that the strain rate tensor derives from pseudo-potential, function of the stress field, and is proportional to a scalar function that describes the uniaxial creep law. This scalar function depends on the stress field through an equivalent stress. In this framework, another way to implicitly account for the asymmetry is to build an equivalent stress that intrinsically includes this effect, for instance by introducing a dependency to the first stress invariant.

Asymmetry in ceramics is often related to damage occurring in the tensile area [19]. However, plasticity models with yield surface dependent on the first stress invariant proved to be able to describe the behaviour of concretes under compression [20]. In particular, Drucker-Prager $[21,22]$ yield surface is often used to model the behaviour of confined concretes [23-25], and less frequently the creep behaviour of refractories [26,27].

An important consequence of these models is that the assumption of creep incompressibility is not consistent with the hypothesis of normality $[22,28]$ if the equivalent creep stress depends on the first stress invariant [29]. However, according to Vermeer and de Borst [30], for materials such as soils, rocks and concretes, experiments have disproved the hypothesis of normality. It is therefore mandatory to investigate the associativity of the creep flow.
Table 1

Composition of the refractory castable.

\begin{tabular}{ll}
\hline Component & Composition (wt.\%) \\
\hline $\mathrm{Al} 2 \mathrm{O} 3$ & 85 \\
$\mathrm{SiO} 2$ & 10 \\
$\mathrm{CaO}$ & 1.1 \\
$\mathrm{Fe} 2 \mathrm{O} 3$ & 1 \\
Water requirement & $4.2-5.2$ \\
\hline
\end{tabular}

Theoretical developments describing the creep asymmetry as a consequence of an anisotropic kinematic hardening, have been applied to secondary [31] or primary creep [32] of metallic alloys. In the present study, only monotonic behaviours will be considered, and the strain hardening will be assumed to be isotropic (as it is the case for soils [22]). Indeed the creep strain rate is very small and the Bauschinger effect, if any, is expected to become significant very late. However, it is noteworthy that the neutral axis shift toward the compressed area due to asymmetric creep implies that an amount of material initially under compression will later undergo tension, as described in Ref. [13]. This phenomenon will not be considered in this paper and bending tests will be considered as monotonic.

The present study aims at contributing to understand the stress field change and the neutral axis shift while bending creep, by combining both experimental and simulation approaches.

It is proposed in this paper to investigate the capability of a Drucker-Prager creep model to describe the asymmetric behaviour of a fibre reinforced refractory concrete assuming an isotropic hardening. An original calibration method is proposed to identify the model parameters from compression and bending data considering two extreme assumptions: in the first case, the flow is assumed to be associated (and thus dilatant), whereas the second one assumes a non-dilatant flow (and thus non-associated). The validity of these assumptions is discussed by comparing the experimental results to the numerical simulations.

\section{Material and methods}

\subsection{Material}

The material under study is a commercial refractory castable reinforced with 2 wt.\% of FeCrAl hooked-end fibres (length $25 \mathrm{~mm}$, diameter $0.7 \mathrm{~mm}$ ). The concrete is constituted of bauxite aggregates (size between $0.2-5 \mathrm{~mm}$ ), dispersed in commercial ultra low cement bauxite matrix (Table 1 ), composed of bauxite particles lower than $200 \mu \mathrm{m}$ in diameter, $8 \mathrm{wt} . \%$ of calcium alumina cement, fumed silica and $\alpha$-alumina. The material is characterised by an open porosity of $10 \mathrm{vol} . \%$ and an apparent density of $2970 \mathrm{~kg} \mathrm{~m}^{-3}$. A more detailed description of this material is available in [13].

\subsection{Elasticity properties}

The elasticity properties of the material were measured by impulse excitation of vibration method [33]. The Young's modulus of three $16 \times 40 \times 25 \mathrm{~mm}^{3}$ samples was measured in bending configuration up to $1050^{\circ} \mathrm{C}$ (the maximum temperature of the device) at $3{ }^{\circ} \mathrm{C} \cdot \mathrm{min}^{-1}$. The dilatometric behaviour of the matrix is stable enough [34] to consider that the modulus should not vary significantly up to $1200^{\circ} \mathrm{C}$, the temperature of the creep tests performed in this study. Moreover, the instantaneous strains and deflections will be subtracted from all experimental and numerical data considered for calibration purpose. The effect of elasticity is therefore expected to be only of the second order. A value of $45 \mathrm{GPa}$ will be considered for the Young's modulus at $1200^{\circ} \mathrm{C}$, with a $\pm 2 \mathrm{GPa}$ dispersion related to the material heterogeneity. The shear modulus was measured at room temperature in a torsional configuration. 
The value of the Poisson's ratio at room temperature, 0.1 , has been assumed to stay constant with temperature. It is noteworthy that the Young's modulus of this kind of materials is the same in tension and compression [35]. The elastic part of the strain is therefore linear isotropic and symmetric, following the generalized Hooke's law.

\subsection{Bending creep experiment}

The bending data used in this study are those described in a previous paper [13] (the same batch of concrete was used) and provide the neutral axis location after bending creep at $1200^{\circ} \mathrm{C}$. This temperature is high enough to involve creep without macroscopic damage [13] and is just below the onset of an important shrinkage of the matrix [34]. The bending specimens $\left(35 \times 40 \times 165 \mathrm{~mm}^{3}\right)$ were cast under vibrations and kept in the mould for $24 \mathrm{~h}$ at room temperature until the concrete sets. The specimen are then dried at $110^{\circ} \mathrm{C}$ for $24 \mathrm{~h}$ and fired at $1200^{\circ} \mathrm{C}$ for $30 \mathrm{~h}$. Finally, the four faces of the specimen are ground to get plane and parallel bearing surfaces and obtain a relevant texture to perform 3D-DIC measurements.

\subsection{Compressive creep experiment}

The bending data are useful as they involve tension in the material. To complete these experiments, compression tests have been performed at $1200^{\circ} \mathrm{C}$ with alumina plates using the same setup as depicted in [36]. The specimens were $40 \mathrm{~mm}$ in height and $25 \mathrm{~mm}$ in diameter and were machined in a bending specimen with a diamond drill bit. The creep duration was $11 \mathrm{~h}$ for specimens under compressive stress levels of 3, 4, 5 and $6 \mathrm{MPa}$. Another test at $3 \mathrm{MPa}$ for $25 \mathrm{~h}$ was also perform to assess the repeatability of the experiment and investigate the limit of the primary creep.

Friction plays a non-negligible role in the compression tests, as non-desired mechanism of dissipation, involving shear stresses and non-uniform loading. The coefficient of kinetic friction between a concrete pin with a $25 \mathrm{~mm}$-radius spherical contact surface and an alumina plate with the same roughness as the compression plates was measured at room temperature. A mean value of $0.28 \pm 0.03$ was obtained with a normal load of $1 \mathrm{~N}$ and a linear sliding speed of $2 \mathrm{~mm} \cdot \mathrm{s}^{-1}$. Another test at $1 \mathrm{~m} \cdot \mathrm{s}^{-1}$ has shown that the coefficient of friction is first of the same value, but quickly increases up to 1 and more, probably under the effect of temperature increase. Two assumptions will therefore be compared in the numerical analysis: a sliding contact (Coulomb model) with a coefficient of friction of 0.28 , and a sticky contact.

\section{Model}

The creep model used in this study is a built-in function of the commercial software ABAQUS/Standard and detailed in the user manual. A brief description is given here in order to clearly state the assumptions made. This section also provides a description of the numerical simulation of the experiments performed with ABAQUS/Standard. In this model, the strain tensor is additively decomposed into an elastic component and a creep component.

\subsection{Uniaxial primary creep law}

As explained previously in the introduction, the processing of bending data necessitates considering the primary creep to properly compute the stress field in the specimen during the whole test even if a stationary creep arises. It is also important for compression tests since friction at the contact with the plates induces a triaxial state of stress that imply that the stationary creep, if any, is not reached simultaneously in the whole specimen. The creep law
Table 2

Values of $A_{1}, m$ and $n$ identified in the first one-dimensional case.

\begin{tabular}{lll}
\hline$A_{1}\left(\mathrm{MPa}^{-\mathrm{n}} \mathrm{s}^{-(\mathrm{m}+1)}\right)$ & $m$ & $n$ \\
\hline $2.5710^{-5}$ & -0.593 & 0.716 \\
\hline
\end{tabular}

considered here is a usual 3 parameters creep law with strain hardening, Eq. (1), including a Norton-type stress contribution, usually used for refractories creep modelling [37].

$\dot{\varepsilon}^{c r}=\left[A(\sigma)^{n}\left[(m+1) \varepsilon^{c r m \frac{1}{m+1}}\right.\right.$

\subsection{Drucker-Prager primary creep law}

\subsubsection{Equivalent creep stress}

The tension/compression asymmetric creep behaviour of the refractory concrete is modelled using a Drucker-Prager creep law. The Drucker-Prager creep is an extension of the Drucker-Prager plasticity criterion $[21,22]$ that assumes that the creep intensity depends not only on Mises equivalent stress $q$ (function of the second stress deviator invariant) but also on pressure $p$ (function of the first stress invariant). The tension/compression asymmetry thus derives from a pressure effect and is not an effect of the third invariant. The advantage of this model is that the creep law is the same in tension and compression, allowing a reduced number of parameters. The model introduces an equivalent stress $\bar{\sigma}^{c r}$, Eq. (2), function of $q$ and $p$. Eq. (2) is the expression of the equivalent stress when the model is calibrated from uniaxial compression data. Indeed, for a compressive uniaxial state of stress $(\sigma<0)$, Eq. (2) reduces to $\bar{\sigma}^{c r}=-\sigma$, whereas for a tensile uniaxial state of stress $(\sigma>0)$, it leads to $\bar{\sigma}^{c r}=\sigma \frac{1+\frac{1}{3} \tan \beta}{1-\frac{1}{3} \tan \beta}>\sigma$. For a given absolute value of the uniaxial stress $\sigma$, the equivalent stress is therefore higher in tension than in compression implying a higher creep rate in tension.

$\bar{\sigma}^{c r}=\frac{q-p \tan \beta}{1-\frac{1}{3} \tan \beta}$

This model implies that any state of stress with the same equivalent stress induces the same creep intensity. In the meridional stress plane ( $p-q$ plane), the states of stress with the same equivalent stress are defined by a straight line passing through the actual $(p, q)$ point and making an angle $\beta$ with the $p$-axis. $\beta$ is the material angle of friction. In the deviatoric stress plane, the equivalent-creep surface thus defined is the Mises circle.

It is noteworthy that if $q \leq p \cdot \tan (\beta)$ (and assuming 1 $\frac{1}{3} \tan \beta>0$ ), then $\bar{\sigma}^{c r} \leq 0$, what means that the material do not creep. The states of stress involving a high hydrostatic pressure, for which the model would predict no creep, do not fall into the scope of the present model, only identified in bending and uniaxial compression.

\subsubsection{Creep flow}

The creep flow derives from a hyperbolic pseudo-potential $G^{c r}$, Eq. (3), defined by three parameters: the dilation angle at high confining pressure, $\psi$, the eccentricity, $\varepsilon$, that defines the curvature of the potential, and the initial yield stress, $\bar{\sigma}_{0}$, that must be set high enough in the present case to prevent plasticity and activate only a creep behaviour. This pseudo-potential is hyperbolic in the $p-q$ plane and corresponds to the Mises circle in the deviatoric stress plane, and limits the model to isotropic hardening.

$G^{c r}=\sqrt{\left(\varepsilon \bar{\sigma}_{0} \tan \psi\right)^{2}+q^{2}}-p \tan \psi$

This potential form is continuous and smooth, especially at the intersection with the $p$-axis, and asymptotically approaches the 


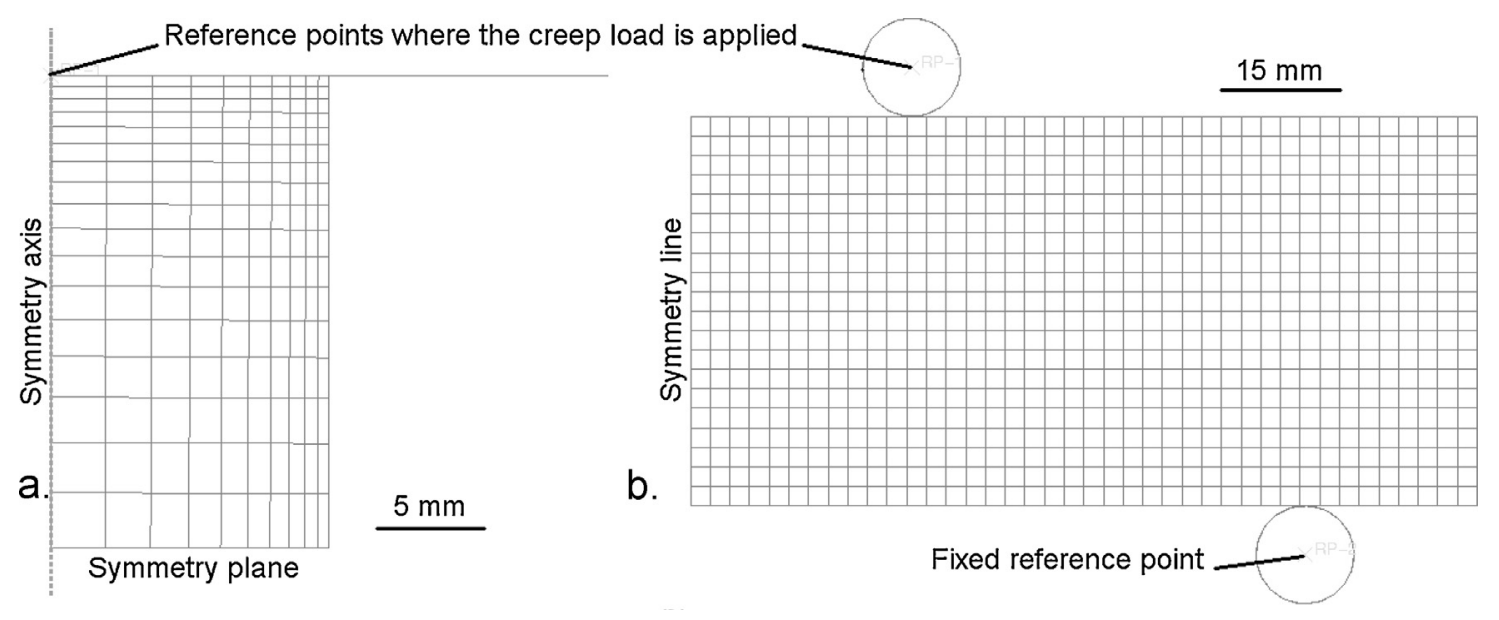

Fig. 1. Meshes, boundary conditions and load application points for compressive (a) and bending (b) creep simulations.

equivalent-creep surface. In the present case, only bending and compressive data are considered. Therefore the potential will be chosen as close as possible to the equivalent-creep surface by setting arbitrarily the eccentricity parameter to the minimum value allowable, $10^{-6}$. In such conditions, except in the vicinity of the $p$ axis, the potential is very close to a straight line passing through the actual $(p, q)$ point and making an angle $\psi$ with the $p$-axis, and the potential is mainly defined by the value of the dilation angle.

As discussed in the introduction, the dilatancy of the flow is a key feature of the creep behaviour when the first stress invariant is introduced in the equivalent creep stress. Two assumptions are considered in the paper. First, the assumption of creep incompressibility is formulated, leading to a non-dilatant flow with $\psi=0$ (the potential only depends on $q$ ). Then the hypothesis of normality will be assessed by setting the dilation angle to the friction angle value, $\psi=\beta$. It is noteworthy that even with the minimum value of the eccentricity, the flow is not exactly associated, especially in the vicinity of the $p$-axis.
The uniaxial creep law, Eq. (1), is translated to the triaxial case,

Eq. (4), and relates the equivalent creep strain rate, $\bar{\varepsilon}$, to the equivalent creep stress, $\bar{\sigma}^{c r}$, and the equivalent creep strain, $\bar{\varepsilon}^{c r}$, in order to account for the non-linear primary creep through an isotropic strain hardening.

$\bar{\varepsilon}^{\cdot c r}=\left[A \bar{\sigma}^{c r}\right)^{n}\left[(m+1) \bar{\varepsilon}^{c r m} \frac{1}{m+1}\right.$

.cr

From Eq. (4), the scalar equivalent creep strain rate, $\bar{\varepsilon}$, can be computed at each time step, and contributes to calculate the creep strain rate tensor $\underset{{ }_{\text {cr }}}{\overline{\bar{\varepsilon}}}$, calculated from Eq. (5), where $f^{c r}$ is defined in such a way that $\overline{\bar{\varepsilon}}$ is work conjugate to $\overline{\bar{\sigma}}$, Eq. (6), as well as $\bar{\varepsilon}$ is work conjugate to $\bar{\sigma}^{c r}$ (cf. ABAQUS Theory Manual for further details on the numerical integration of these equations by the backward Euler method, selected through the activation of geometrically nonlin-

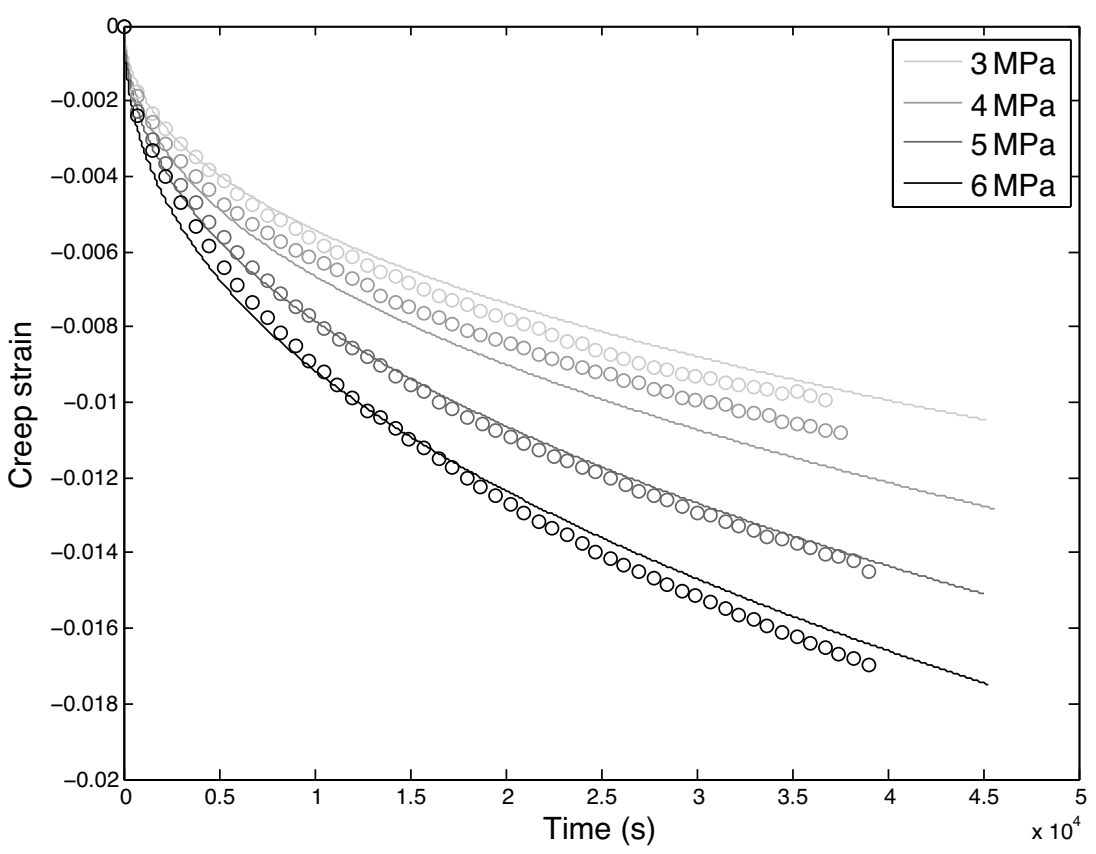

Fig. 2. Comparison of experiment (o) with the creep model (-) calibrated assuming unidirectional compression. 


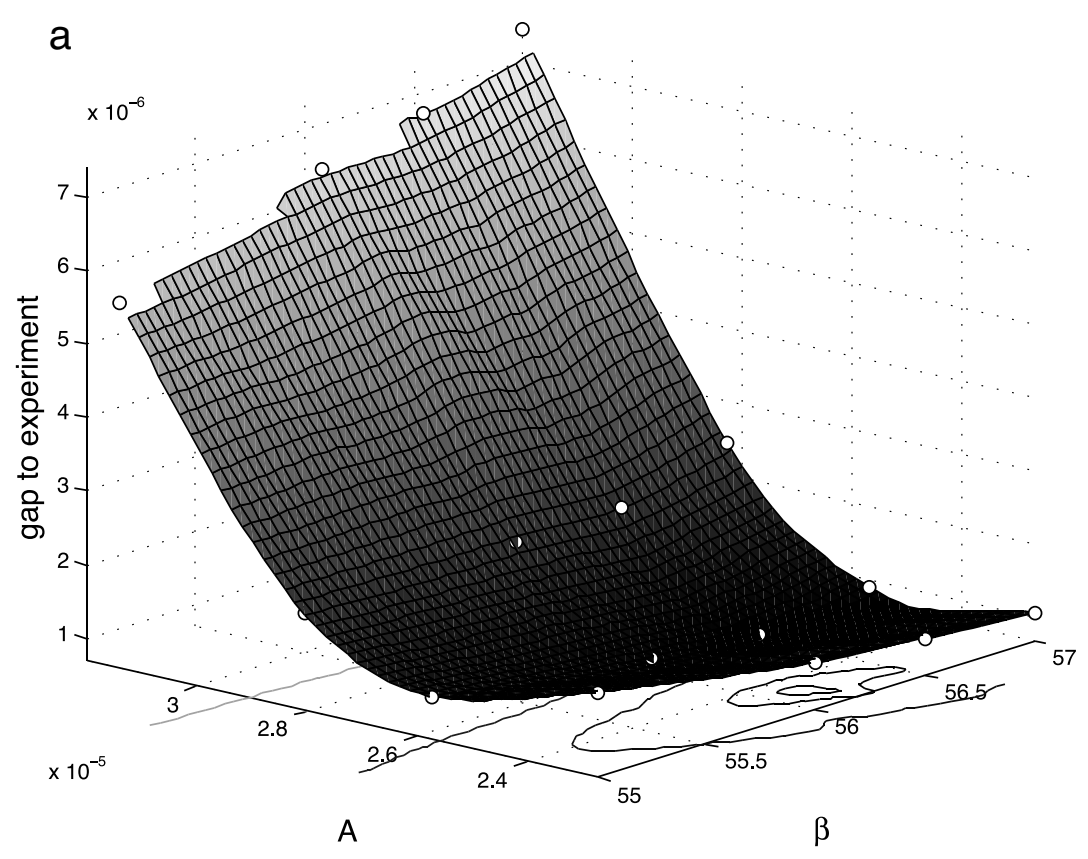

b

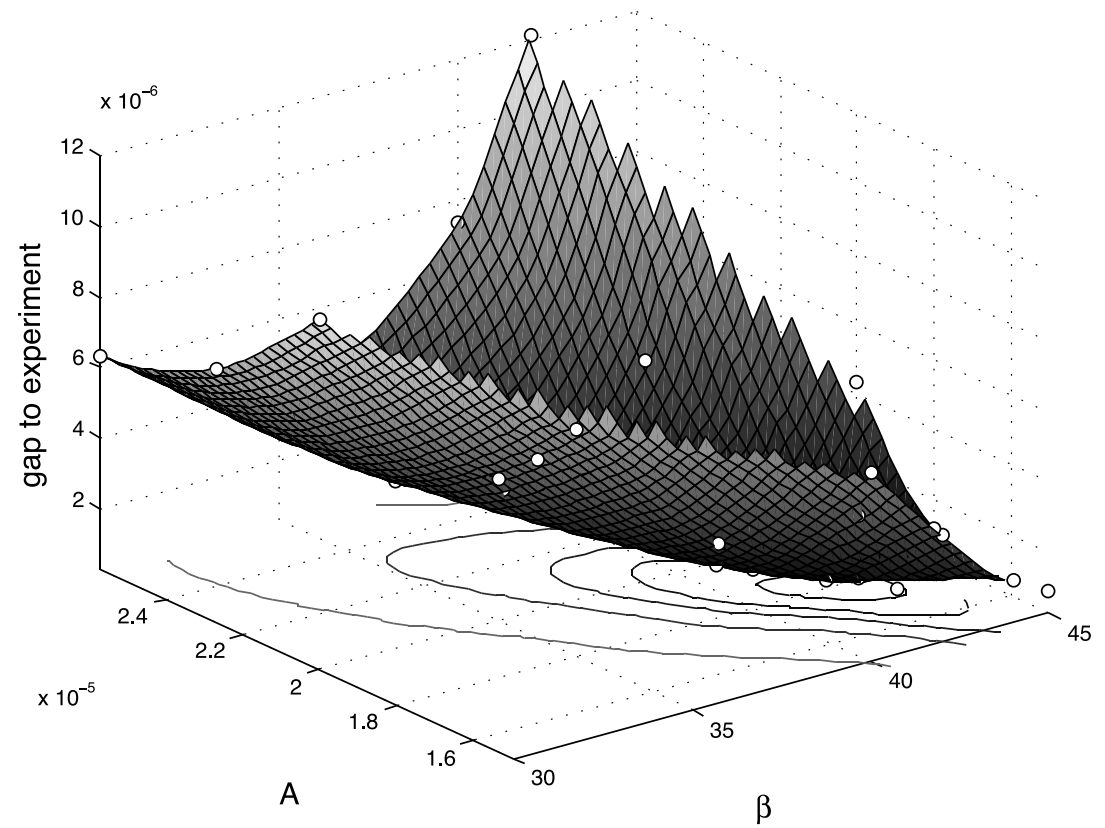

Fig. 3. Least square gap (arbitrary unit) between simulated and experimental strain fields as a function of $A\left(\right.$ unit $\left.\mathrm{MPa}^{-\mathrm{n}} \mathrm{s}^{-(\mathrm{m}+1)}\right)$ and $\beta\left({ }^{\circ}\right)$ assuming (a) a non-dilatant flow and (b) an associated flow.

ear analyses even if only small strains are involved in the problems under consideration).

$\stackrel{=c r}{\varepsilon}=\frac{\bar{\varepsilon} c r}{f^{c r}} \frac{\partial G^{c r}}{\partial \overline{\bar{\sigma}}}$

$f^{c r}=\frac{1}{\bar{\sigma}^{c r}} \overline{\bar{\sigma}}: \frac{\partial G^{c r}}{\partial \overline{\bar{\sigma}}}$

\subsection{Finite element computations}

The numerical simulations of the compression creep tests were carried out with axi-symmetric elements and a symmetry plane was defined at the mid-height of the specimen, as depicted in Fig. 1a. The compression plate was schematised as a discrete rigid body and a load is applied on it. The $12.5 \times 20 \mathrm{~mm}^{2}$ rectangular geometry was meshed with 170 linear quadrilateral elements by considering a single bias in both directions in order to ensure a finer element size in the vicinity of the edge of the specimen, in 


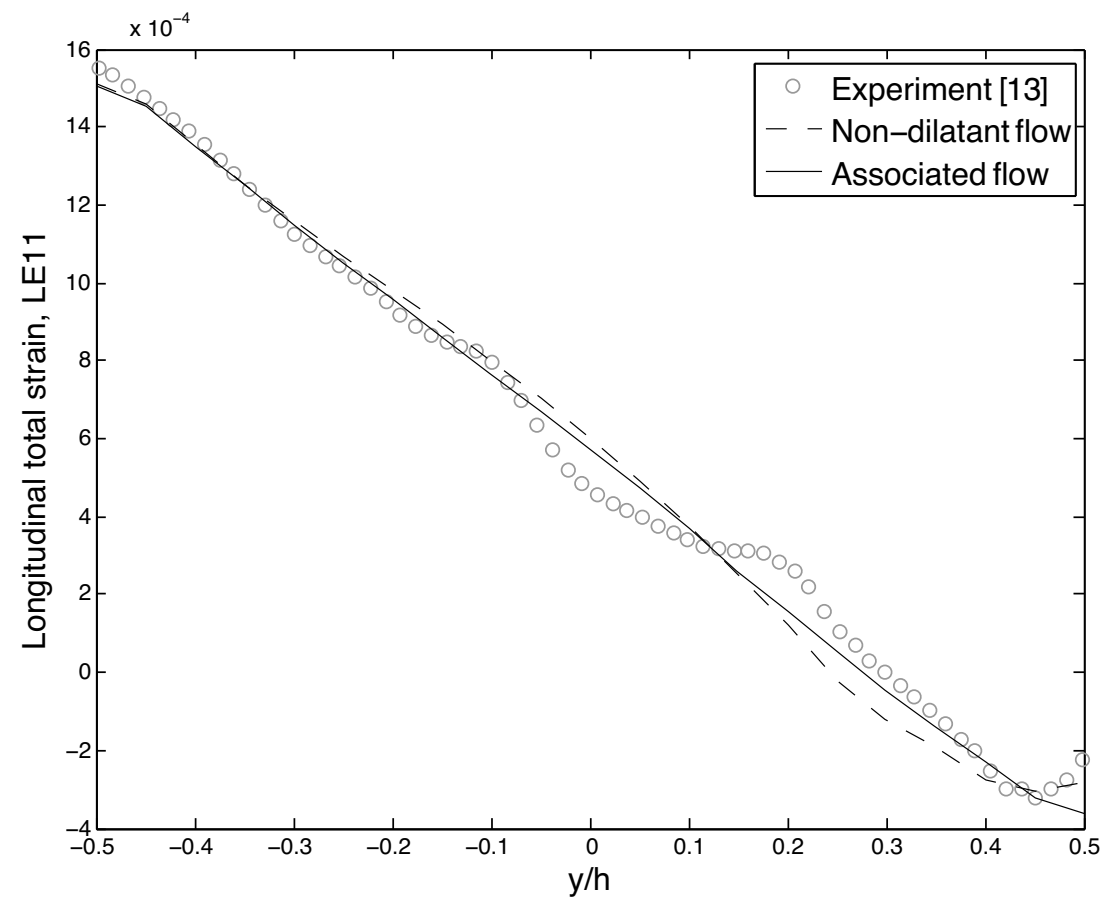

Fig. 4. Comparison of the longitudinal total strain field in the bending specimen computed at the end of creep test and measured after unloading assuming a non-dilatant or an associated flow.

contact with the compression plates. The length of the element edge thus ranges between 0.4 and $2 \mathrm{~mm}$ (the simulations provide similar results using a twice finer mesh).

The numerical simulations of the bending creep tests were performed with plane strain elements and a symmetry plane was defined in the mid-length of the specimen, as depicted in Fig. 1b. The support and loading points are $12 \mathrm{~mm}$ diameter arcs of circle schematised as analytical surfaces. The former is fixed and a load of $200 \mathrm{~N}$ is applied on the latter. The results reported in Section 4 for the calibration of the model were obtained by meshing the $40 \times 80 \mathrm{~mm}^{2}$ rectangular geometry with 800 linear $2 \mathrm{~mm}$ edge square elements. Indeed, a sensitivity analysis to the mesh size (performed a priori with arbitrary parameters values and $a$ posteriori with the optimal set of parameters) showed that the strain field at the symmetry plane is not sensitive to the element size: after a creep step of $25 \mathrm{~min}$, the discrepancy between the minimal strain obtained with a mesh size of $2 \mathrm{~mm}$ and $0.5 \mathrm{~mm}$ is about $2 \%$, and lower than $1 \%$ for the maximal strains. The strain field being linear, the neutral axis location is therefore insensitive to the mesh size.

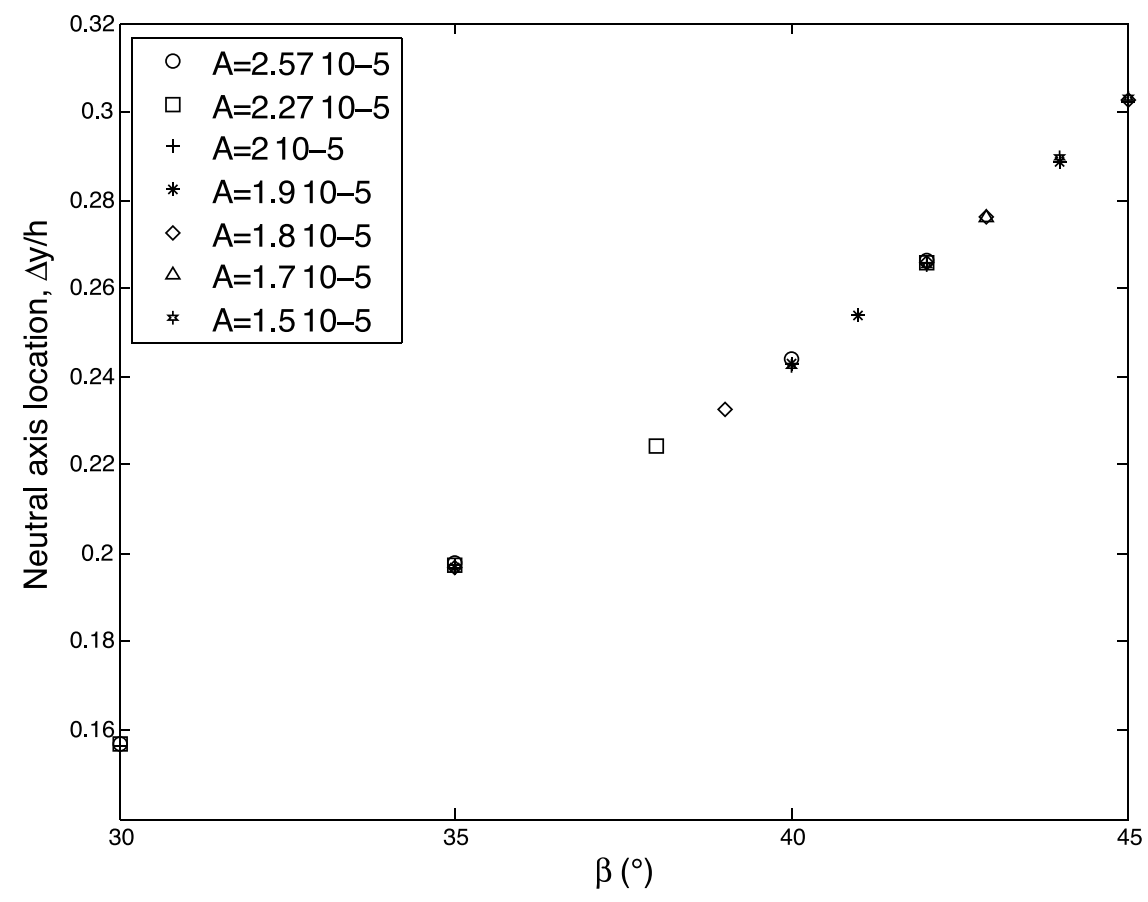

Fig. 5. Neutral axis location $(\Delta y / h)$ as a function of $\beta$ and $A$ assuming an associated flow. 
Table 3

Values of $A_{2}$ and $\beta$ identified from bending creep full-field measurements.

\begin{tabular}{lcll}
\hline Assumption & $\psi\left({ }^{\circ}\right)$ & $A_{2}\left(\mathrm{MPa}^{-\mathrm{n}} \mathrm{s}^{-(\mathrm{m}+1)}\right)$ & $\beta\left(^{\circ}\right)$ \\
\hline Non-dilatant flow & 0 & $2.5710^{-5}$ & 56.5 \\
Associated flow & 42.9 & $1.8010^{-5}$ & 42.9 \\
\hline
\end{tabular}

In contrast, the bending creep results reported in Section 5 and computed with the optimal set of parameters, were obtained with a mesh size of $0.5 \mathrm{~mm}$. Indeed, the specimen deflection turns out to be sensitive to the mesh size, because of the material deformation at the contact with the support and loading points: a discrepancy of $13 \%$ is obtained considering element sizes of 0.5 and $2 \mathrm{~mm}$ (the error is estimated at $15 \%$ for $2 \mathrm{~mm}$ and $1.4 \%$ for $0.5 \mathrm{~mm}$, assuming a quadratic fit of the deflection computed with an element size of $0.5,1,1.5$ and $2 \mathrm{~mm}$ ). Moreover the computation time is not so important here since only one computation is performed.

In all cases, the load was applied on the reference point that controls the motion of the rigid body and the analytical surface, i.e. respectively the compression plate and the upper loading point. The contact between the specimen and the rigid bodies assumes either sliding with a coefficient of friction of 0.28 or a sticky contact.

\section{Results of model calibration}

The methodology involved to identify the parameters of the Drucker-Prager creep law includes three steps. The compression data are first processed as one-dimensional creep to identify the parameters of the creep law, $m$ and $n$, and to assess a first value $A_{1}$ of parameter $A$. The angle of friction $\beta$ of the material is then identified from kinematic full-field measurements performed during interrupted bending creep tests, to account for the shift of the neutral axis location. Finally, the compression tests are simulated to take friction with the plate into account and identify the final value of $A$.

\subsection{One-dimensional calibration}

A first set of parameters was identified using a one-dimensional model consisting in a numerical integration of Eq. (1) using the trapezoidal rule. The experimental stress is imposed as boundary condition. A Newton algorithm was used to identify the values of parameters $m$ and $n$ and a first value $A_{1}$ of parameter $A$, considering the four compressive tests at $1200^{\circ} \mathrm{C}$ under nominal stress levels of 3, 4, 5 and $6 \mathrm{MPa}$.

Fig. 2 compares the experimental data and the results of this model obtained with the optimum set of parameters reported in Table 2. Considering the unavoidable scattering inherent to the characterisation of heterogeneous materials, a very proper agreement is observed over the whole duration of the tests irrespective of the experiment under consideration, with a maximum gap lower than $9 \%$ for the $4 \mathrm{MPa}$ curve and lower than $6 \%$ for the other curves. The form of the creep law, Eq. (1), is thus able to properly account for the hardening occurring during the primary creep under compression.

Table 4

Values of $A$ identified from compressive creep experiments.

\begin{tabular}{llccc}
\hline Flow assumption & Contact & $\psi\left({ }^{\circ}\right)$ & $A\left(\mathrm{MPa}^{-\mathrm{n}} \mathrm{s}^{-(\mathrm{m}+1)}\right)$ & $\beta\left(^{\circ}\right)$ \\
\hline Non-dilatant flow & Sliding with friction & 0 & $3.1810^{-5}$ & 56.5 \\
Associated flow & Sliding with friction & 42.9 & $3.0110^{-5}$ & 42.9 \\
Associated flow & Sticky & 42.9 & $3.5410^{-5}$ & 42.9 \\
\hline
\end{tabular}
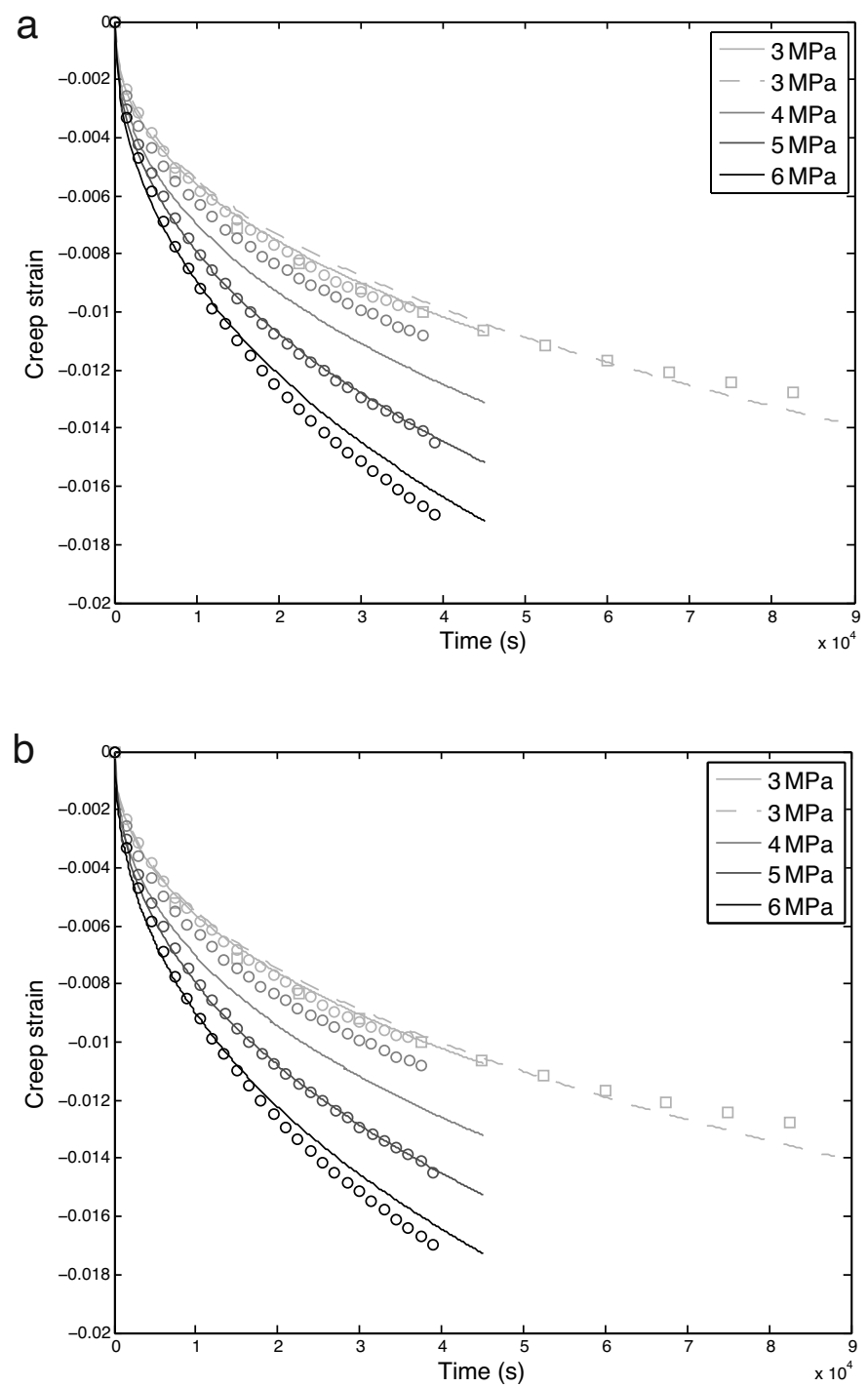

C

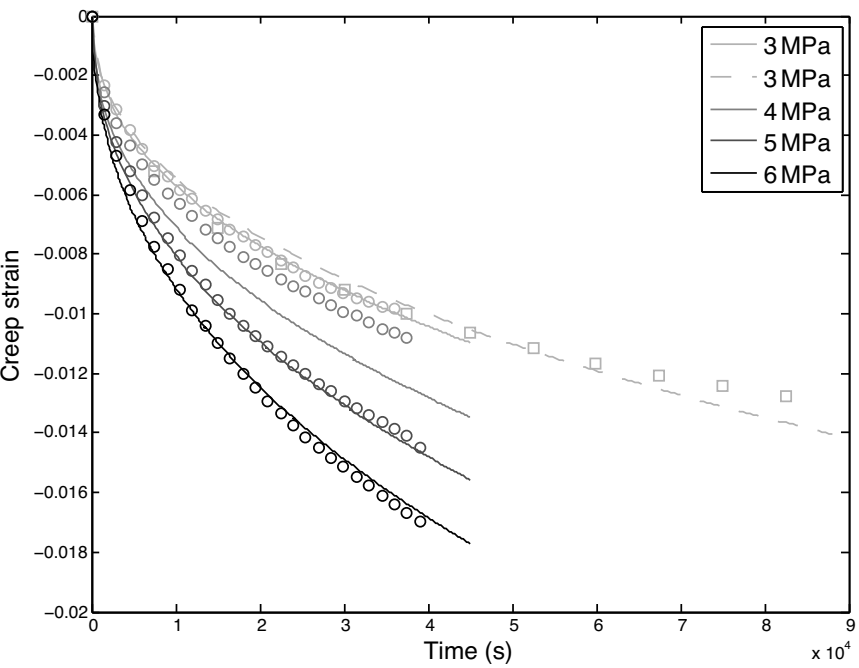

Fig. 6. Comparison of experimental (circles and squares) and simulated (lines) compressive creep behaviours assuming (a) a non-dilatant flow and a sliding contact between the specimen and the plates, (b) an associated flow and a sliding contact between the specimen and the plates and (c) an associated flow and sticky contact between the specimen and the plates. 


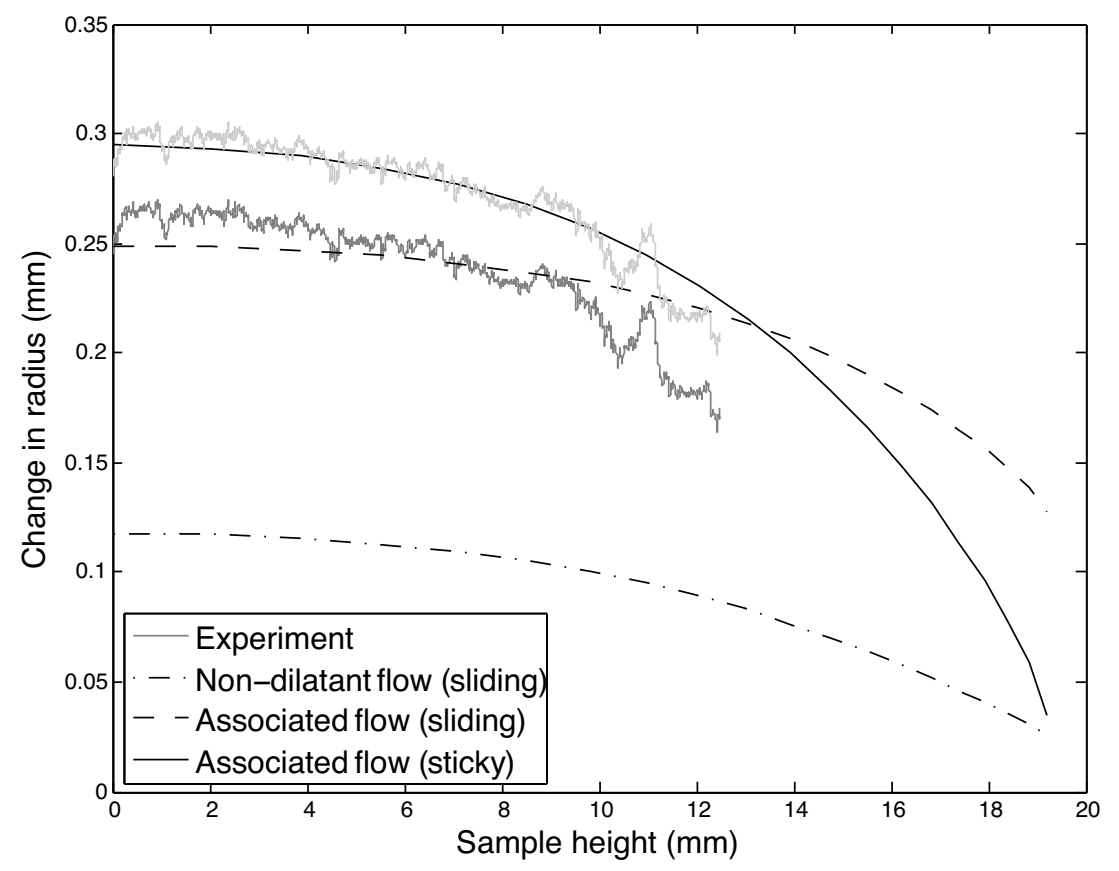

Fig. 7. Anamorphic view of the sample profile after compressive creep under $3 \mathrm{MPa}$ for $25 \mathrm{~h}$ at $1200^{\circ} \mathrm{C}$ : experimental data and simulated profiles assuming a non-dilatant flow and a sliding contact, an associated flow and a sliding contact or an associated flow and a sticky contact (the light grey experimental curve is a translation of the raw experimental one in dark grey and highlights that the curvature is very close to the simulation assuming an associated flow and a sticky contact).

\subsection{Identification of the angle of friction $\beta$}

The angle of friction $\beta$ is the parameter that controls the sensitivity of the equivalent creep stress to the pressure, and thus controls the creep asymmetry, assessed in this study through the neutral axis location measured in the interrupted bending experiment reported in [13]. As the equivalent creep stress depends on $\beta$, the value of this parameter may be calibrated together with the parameter $A$ to ensure that the creep strain rate remains the same when changing $\beta$ (and thus still matches the experimental creep curves). The parameter $m$ of the creep law can keep the same value identified in the unidirectional approach, since $\beta$ does not affect the isotropic hardening. It was also verified that the last parameter of the creep law, $n$, could be kept constant to still properly represent the effect of stress. Indeed considering pure compression tests under several loads, the equivalent creep stress is proportional to the Mises equivalent stress (independent on the material parameters), and the effect of changing $\beta$ can be compensated only by adjusting $A$.

Therefore $\beta$ is identified together with a second value $A_{2}$ of parameter $A$. This calibration is performed based upon matching the longitudinal strain field computed along the symmetry line (Fig. 1b) to the experimental strain field reported in [13]. Several simulations of the bending creep experiment were performed varying the values of $A$ and $\beta$ in order to build the response surface of the model, considering both assumptions of non-dilatant flow (Fig. 3a) and associated flow (Fig. 3b).

For each simulation, the longitudinal component of the total strain along the symmetry line (cf. Fig. 1b) was extracted and fitted using a 6-th degree polynomial in order to interpolate the data at the experimental values, and to compute the gap with the experimental strain field using the least square method. The coordinate where the longitudinal component of the total strain is zero was also interpolated using the polynomial fit to compute the location of the simulated neutral axis.
These results are reported in Fig. 3 and show that an optimal value can be found for each assumption, as evidenced by the contour plot under the surfaces. The value $A_{2}$ of parameter $A$ and of $\beta$ corresponding to the optimisation considering both assumptions are summarized in Table 3. This identification shows that the value of $\beta$ is significantly affected by the assumption under consideration. A very high value of $56.5^{\circ}$ is found assuming a non-dilatant flow.

Fig. 4 compares the experimental strain field to the results of both calibrations assuming a non-dilatant flow or an associated flow. A first observation shows that each assumption satisfactorily reproduces the strain field in the areas where the strain is large, i.e. far away from the neutral axis. In the vicinity of the neutral axis, the assumption of associated flow seems closer to the experimental curve but the experimental data may not be accurate enough in this low-strain area to argue the validity of this assumption.

In this approach, it has been assumed that the location of the neutral axis didn't change between the interruption of the creep test (at $1200^{\circ} \mathrm{C}$ ) and the full-field measurement performed at room temperature (the elastic springback and relaxation occurring after unloading and during cooling are not accounted for). This assumption will be discussed further considering the numerical results (Section 5.2).

Therefore $A_{2}$ is not expected to be the actual value of $A$ because the simulation doesn't account for the specimen deformation occurring between the interruption of the creep test and the fullfield measurement. The experimental and simulated strain fields may thus not be the same, and only the location of the neutral axis is assumed to be the same.

Fig. 5 completes the results of Fig. 3a and plots the neutral axis location (parameterized by the ratio between the neutral axis shift $\Delta y$ and the specimen height $h$ ) computed assuming an associated flow, as a function of parameters $\beta$ and $A$. The figure shows that the neutral axis location is a one-to-one function of $\beta$ ranging between 30 and $45^{\circ}$, irrespective of the $A$ value. This result validates the methodology of calibration by showing that even if the value of $A_{2}$ 


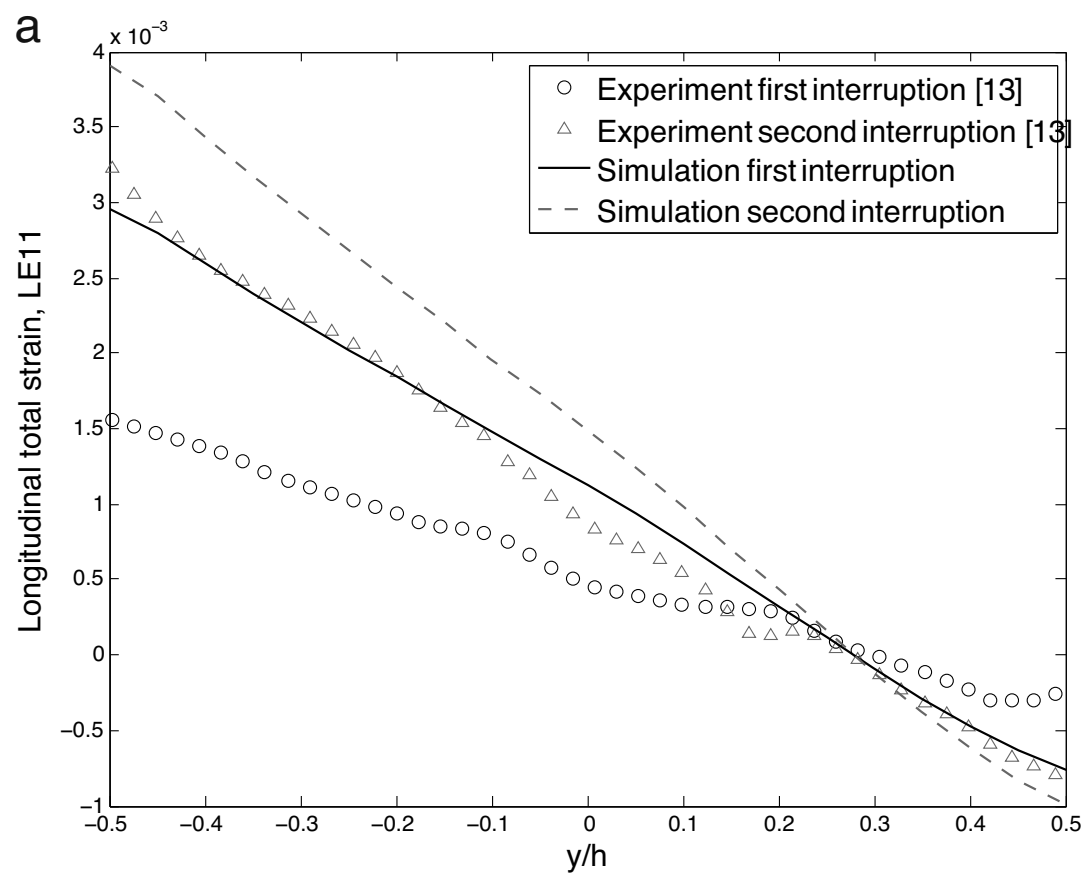

b

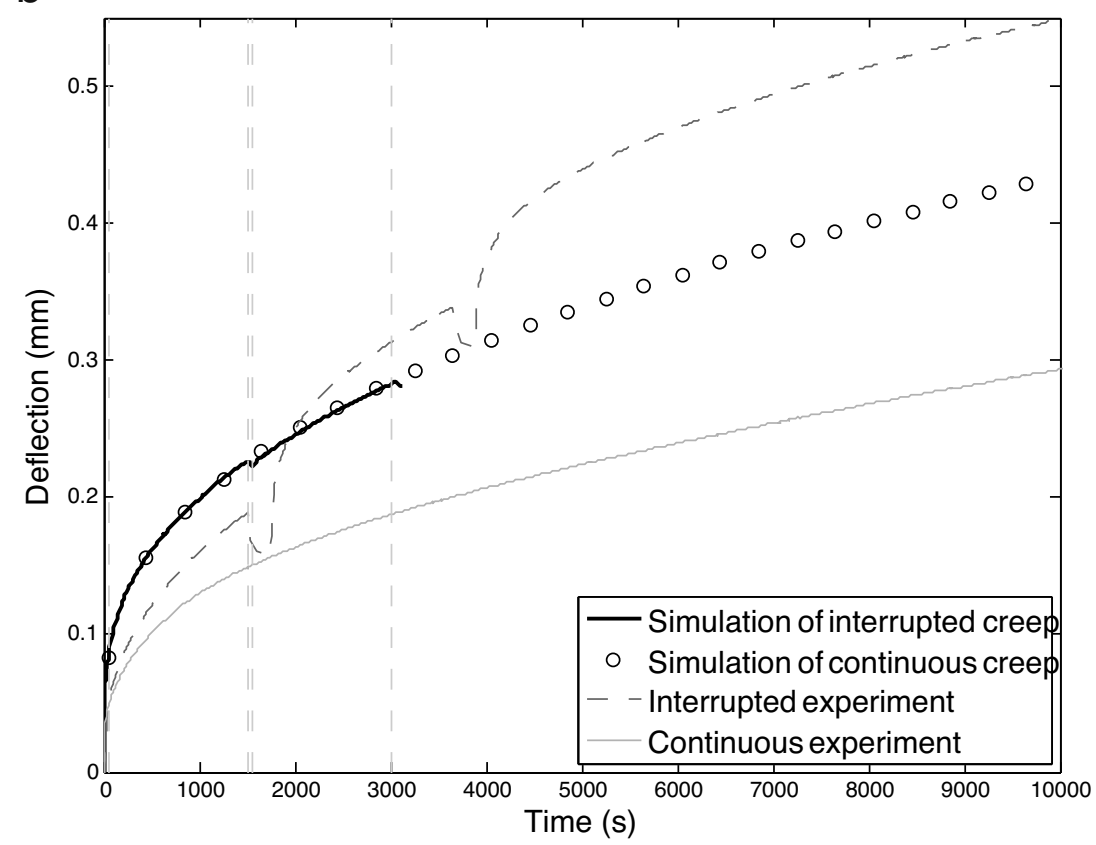

Fig. 8. Comparison of simulated and experimental bending creep: (a) longitudinal total strain fields after the first and the second test interruption and (b) time-deflection curves for the interrupted test (used for full-field measurement) and for a continuous test.

identified in this step is not the final one, the value of $\beta$ is the one that implies the right neutral axis location and thus controls the creep asymmetry. A similar conclusion can be formulated considering the non-dilatant assumption.

\subsection{Calibration of $A$ from compressive creep}

The compressive creep experiments are simulated in ABAQUS/Standard in order to impose proper boundary conditions at the contact between the sample and the plates. The parameters $m, n$, and $\beta$ are set to their value identified previously.
The final value of $A$ is identified in such a way that the simulation matches the compressive creep experiments. For each assumption (dilatant flow with sliding contact, associated flow with sliding contact and associated flow with sticky contact), four Newton iterations are performed to obtain the values reported in Table 4 and provide the same creep curves when compared to experiment (Fig. 6), i.e. a gap lower than $2 \%$ with the unidirectional calibration. It is noteworthy that the comparison to the experimental compressive creep curves provides approximately the same results, depending on the residual of the identification, irrespective of the assumption of unidirectional compression, non-dilatant or 


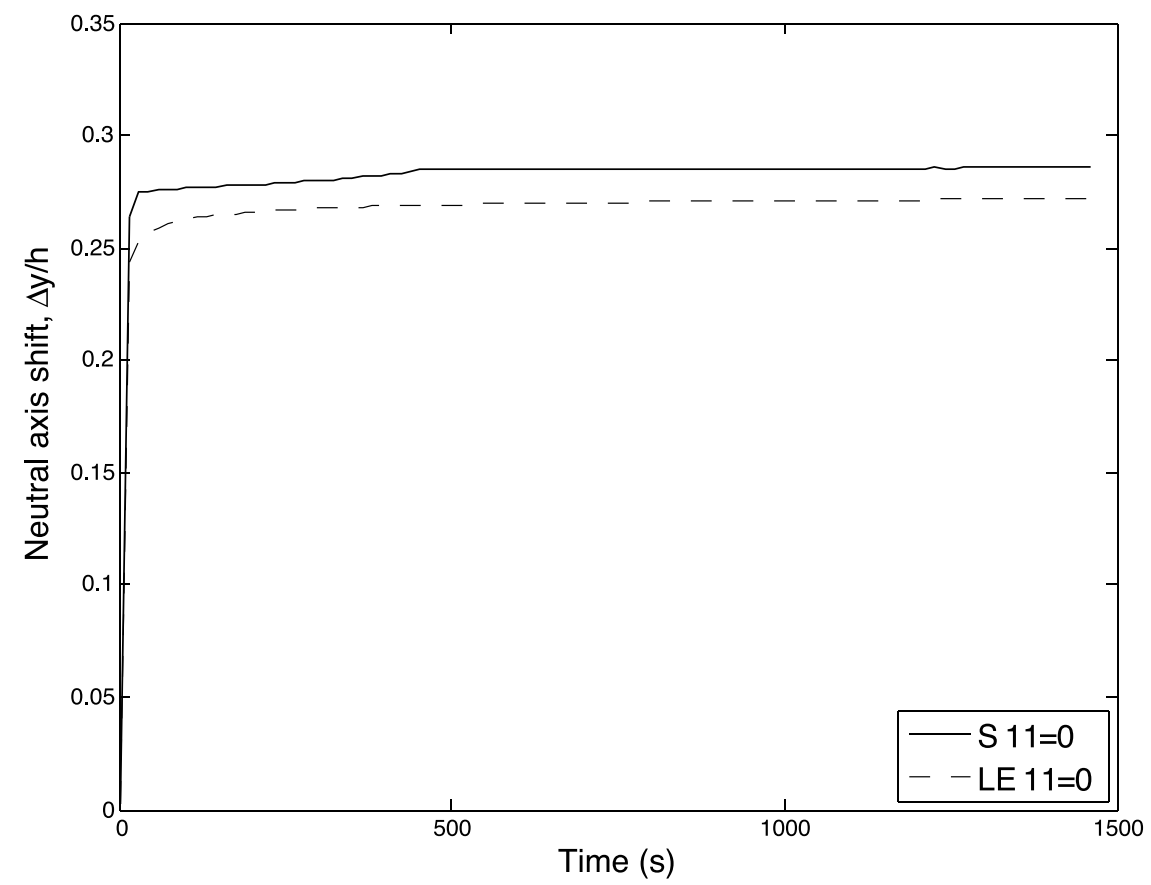

Fig. 9. Neutral axis shift during a bending creep test computed considering the locus of zero stress $(\mathrm{S} 11=0)$ and the locus of zero total strain $($ LE11 $=0)$.

associated flow, which highlights that the compression tests are not sufficient to characterize the creep behaviour of the concrete.

\subsection{Analysis of the sample profile}

In order to further investigate the dilatancy assumption, as well as the actual tribological behaviour during the compressive creep experiments, a simulated sample profile will be compared to an experimental one. The reference experimental sample profile is the average of four linear scans performed along the axis of the sample subjected to a compression stress of $3 \mathrm{MPa}$ for $25 \mathrm{~h}$ (and thus not used for calibration) with an extended field confocal microscope (AltiSurf520, Altimet).

Fig. 7 compares the change in radius along the sample axis obtained from simulation and measured on the compression specimen subjected to $3 \mathrm{MPa}$ for $25 \mathrm{~h}$ at $1200^{\circ} \mathrm{C}$. The experimental profile was measured using the extended field confocal microscope, and was used together with a measurement of the maximal specimen diameter with a micrometer to assess the change in radius. This value is therefore less accurate than the profile itself and an uncertainty on the vertical position of the experimental curve must be considered in Fig. 7. However, the assumption of a nondilatant flow provides an average change in radius significantly lower than the experimental one. In addition, the very good agreement (highlighted by the translated experimental curve) between the experimental profile and the simulated profile demonstrates that both assumptions of sticky contact and associated flow are very realistic, and are the only ones (among the tested assumptions) that allow to accurately account for the compressive creep curves, the neutral axis location and the sample curvature.

\section{Discussion}

In this section, the model results are compared to experiment in order to assess its limits. Finally the discussion will focus on the neutral axis shift during bending creep.

\subsection{Comparison of simulated and experimental bending behaviours}

The creep bending experiment was simulated using the optimized set of parameters, i.e. corresponding to the calibration assuming an associated flow with sticky contact for compression (Table 4). For bending simulation, the sticky contact assumption provides inconsistent results compared to the experimental strain field, and a sliding contact with friction (coefficient of friction of 0.28 ) was therefore assumed, as it was also assumed to identify the value of $\beta$ (Section 4.2). The difference between the contact conditions in both cases, compression and bending, is not surprising considering the different geometries in contact, as well as the different contact pressures and tangential stresses. Moreover the bending loading points are not fastened on their support and may be free to sligthly rotate.

Fig. 8a compares the longitudinal total strain field computed with the aforementioned model during interrupted bending creep to the experimental results reported in [13]. As expected from the discussion of the influence of $\beta$, all curves intersect each other at a strain of zero, and the simulation provides higher strain values due to the high value of $A$ necessary to fit the compression data.

Fig. 8b compares the bending deflection computed considering a continuous bending creep and an interrupted bending creep to experimental data obtained from two different specimens during continuous and interrupted creep. The first rough comparison of simulation and experiment confirms the strain overestimation shown in Fig. 8a since the computed deflection is overall $20 \%$ higher than the experimental one. Considering the available experimental curves, it seems that this cannot result from the material heterogeneity alone. Moreover, the deflection decrease during the unloading, relaxation and cooling steps (partly plotted only for the interrupted experiment) is widely underestimated by the simulation of the unloading step. During the loading steps after test interruption, the experiment shows a significant deflection increase, and the curve tends toward a creep curve parallel to the continuous experiment. The simulation doesn't account for this behaviour and the computed creep curve tends toward the continuous computed behaviour. It is noteworthy that at least part of 

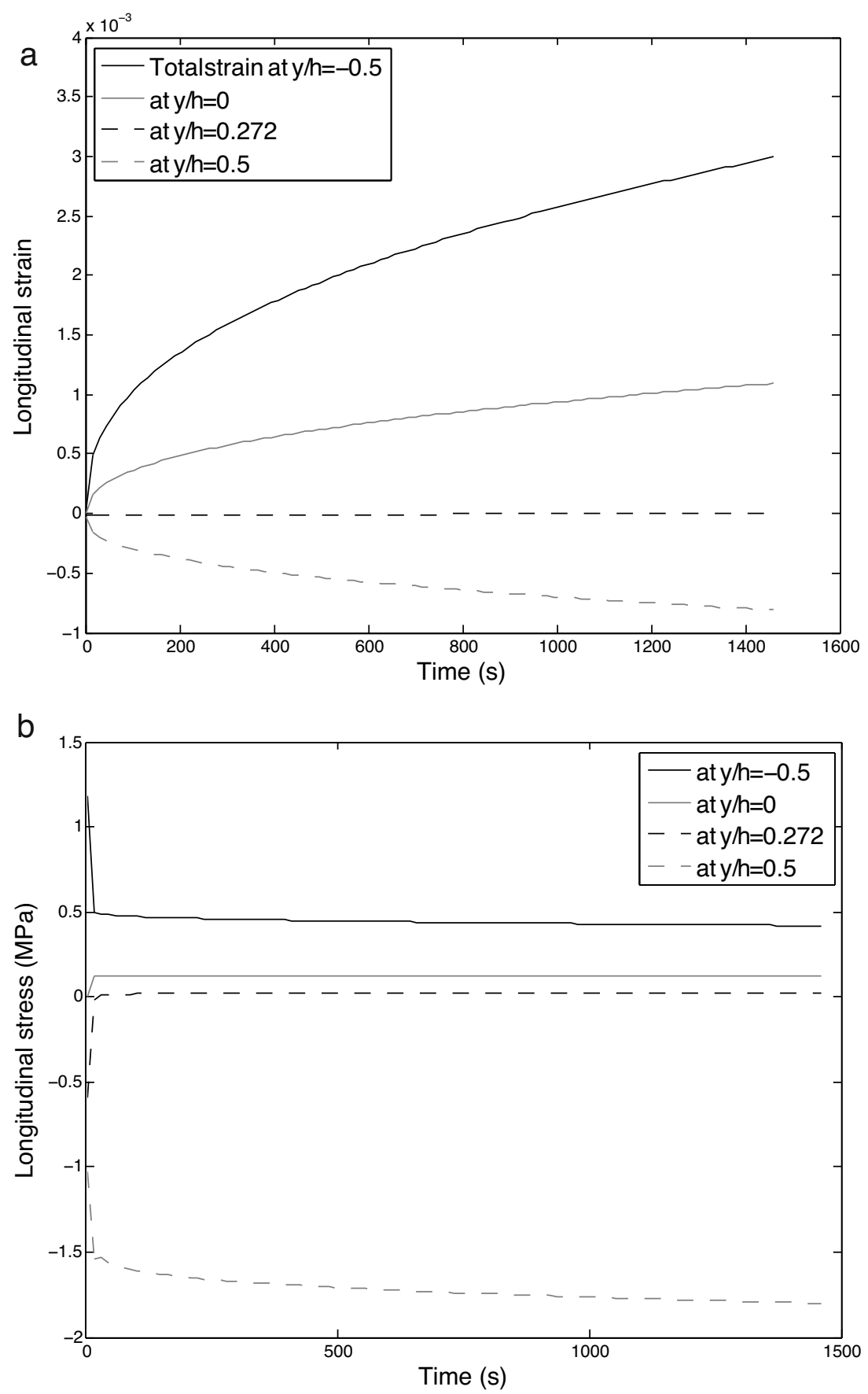

Fig. 10. Change of (a) longitudinal total strain LE11 and (b) of longitudinal stress S11 during a bending creep test at several locations along the specimen thickness $(y / h=-0.5$, $0,0.272$ and 0.5 ).

this behaviour may result from the setup deformation during loading and unloading steps, and also from a compaction of the material at the contact with the support and loading points.

However the assumption of isotropic hardening is here invalidated by the loading behaviour after a creep-unloading sequence. Indeed, the isotropic hardening remains constant during unloading while a kinematic hardening would change. It could indicate that the main mechanism involved during primary creep is related to the motion of hard particles in a glassy matrix, more consistent with a kinematic hardening than an isotropic one. This mechanism is also consistent with the dilatant behaviour of the material if the hard particles are not spherical as it is the case in this material. Nevertheless, under monotonic conditions, the model will be able to properly describe the material behaviour and will be used in Section 5.2 to investigate the neutral axis shift while bending creep.

\subsection{Analysis of the neutral axis shift during bending creep}

The simulation of bending creep allows analysing the shift of the neutral axis. Fig. 9 compares the neutral axis shift during creep (loading not considered) depending on the chosen criterion: locus of zero-stress $(\mathrm{S} 11=0)$ or locus of zero-total strain ( LE11 $=0$ ). Due to the very low elastic strain compared to total strain, the locus of zero-creep strain is very similar to the locus of zero-total strain. The neutral axis at the end of creep is thus very closed to its location after unloading, as assumed in Section 4.2 for the identification 


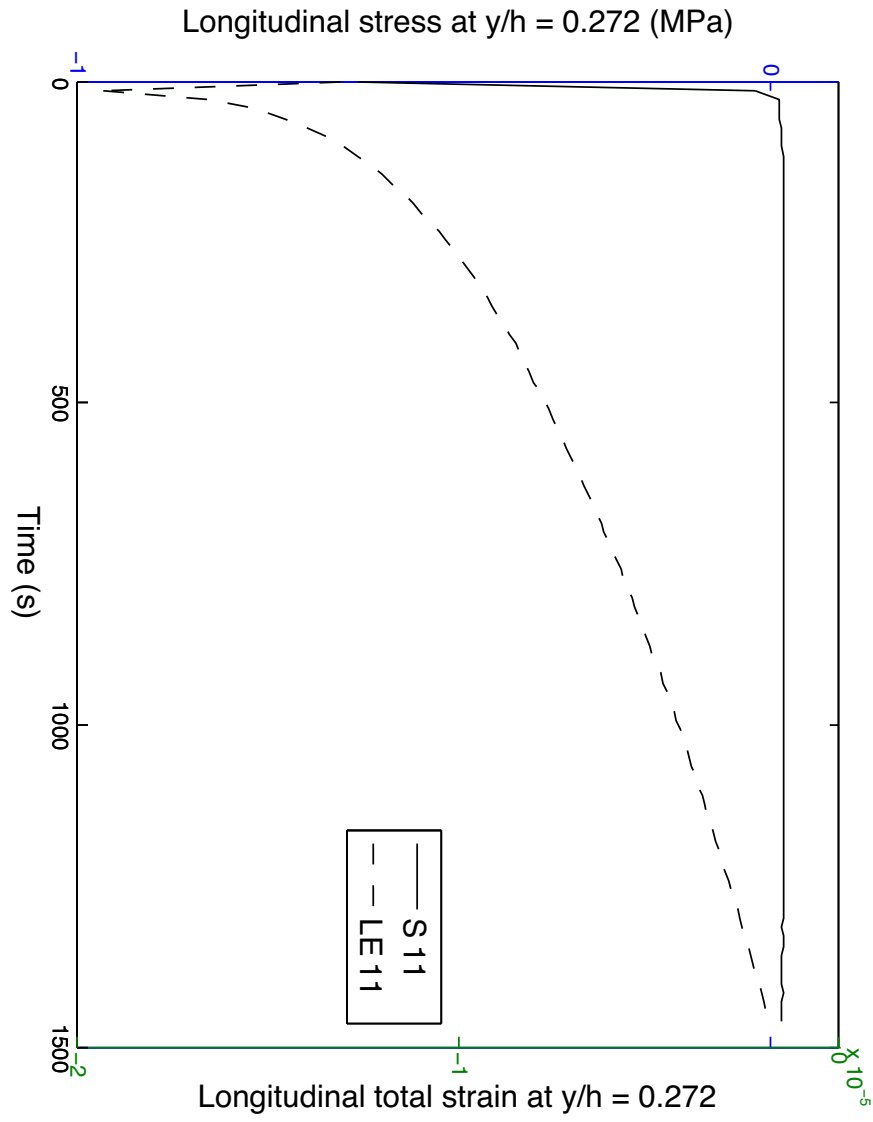

Fig. 11. Variation of longitudinal stress and creep strain at $y / h=0.272$.

of $\beta$. Irrespective of the neutral axis definition, the neutral axis location rapidly stabilizes whereas the deflection curve is still nonlinear. In contrast, Leplay et al. [14] report a significant neutral axis shift together with a perfectly linear bending creep, showing that the asymmetric creep alone doesn't imply that the global bending behaviour is non-linear. It is noteworthy that the final neutral axis location $(\Delta y / h=0.09)$ reported in [14] is much lower than the value found in this study $(\Delta y / h=0.27)$ considering the locus of zero-total strain.

Fig. 10a plots the total strain computed at the mid-plane $(y / h=$ $0)$ and on the lower $(y / h=-0.5)$ and upper $(y / h=0.5)$ faces of the specimen, as well as in the vicinity of the final neutral axis location $(y / h=0.272)$, during creep (loading not considered). The creep strain follows the same evolution at each point. This figure illustrates that the total and creep strains fields remain almost linear in the height of the specimen all along the creep.

In contrast, the stress field change due to creep at the lower and upper faces (Fig. 10b) results in a bilinear profile shape due to asymmetric creep, with a lower slope in the tensile area than in the compressive one, and a tensile area larger than the compressive one. When the creep flow stabilizes, the maximal tensile stress begins to decrease because of a fast creep related to a high equivalent stress; the mean stress in the tensile area therefore tends to decrease, what is counterbalanced by a second shift of the neutral axis (between 300 and $500 \mathrm{~s}$ in Fig. 9).

As shown in [13] using an analytical model of stationary creep, Fig. 11 confirms that an amount of material, initially under compression during the loading step, is finally subjected to tensile stress, as the result of the neutral axis shift. At $y / h=0.272$, the transition from a compressive to a tensile state of stress leads the total strain, initially negative, to tend toward positive values during the creep. This phenomenon may explain why the model overes- timates the creep strain in bending, as this test is not monotonic anywhere in the specimen. The assumption of isotropic hardening would therefore imply some inconstancy in the modelling results.

\section{Conclusions}

This paper reports an analysis of experimental data obtained from simple monotonic compression and bending creep tests at $1200^{\circ} \mathrm{C}$ through the Drucker-Prager creep model. The aim of the study is to assess the capability of the model to properly account for the tension/compression asymmetry evidenced in the creep behaviour of the fibre-reinforced refractory concrete under study. The analysis focuses on the primary creep of the material through an isotropic strain hardening law, assumed a priori.

A multi-steps method is proposed to calibrate this model, using kinematic full-field measurements performed on interrupted bending creep specimens. A calibration method involving only usual tests at high temperature, instead of complex triaxial tests, is of prior interest for technical applications and in order to characterize the creep behaviour over a large temperature range.

The model proved to be able to properly describe the compressive behaviour, together with accounting for the location of the neutral axis of bending specimen, shifted from the mid-plane after creep. It was possible irrespective of the assumption formulated on the dilatancy of the creep flow. However the geometrical characterisation of a compression sample shows that the flow is dilatant, and that the flow pseudo-potential must be built in such a way that the hypothesis of normality holds true (here, dilatancy and friction angles are equal). However, the model is not able to simultaneously reproduce compressive and bending creep curves (the simulated bending deflection is $20 \%$ higher than the experimental one and the simulated strain field is twice the experimental one), because the assumption of isotropic hardening is probably not relevant.

Despite this partial agreement with experimental results, showing that an assumption of kinematic hardening would better describe the behaviour during unloading and reloading, the model allows analysing the neutral axis shift during creep bending. This analysis shows that the neutral axis very quickly stabilizes toward a given location. These results show that simulation is unavoidable to catch the complexity of the stress field change in bending creep, and further build a more relevant model.

\section{Acknowledgement}

The authors greatly acknowledge the contributions of Dr Christine Boher, Mrs Sabine Leroux and Mr Fabrice Rossi to the experimental results.

\section{References}

[1] A.R. Rosenfield, D.K. Shetty, W.H. Duckworth, Estimating tensile creep data from flexure data, J. Am. Ceram. Soc. 69 (1986) 108-109.

[2] H.J. Lim, J.W. Jung, D.B. Han, K.T. Kim, A finite element model for asymmetric creep behavior of ceramics, Mater. Sci. Eng. A 224 (1997) 125-130.

[3] A.A. Wereszczak, M.K. Ferber, T.P. Kirkland, A.S. Barnes, E.L. Frome, M.N. Menon, Asymmetric tensile and compressive creep deformation of hot-isostatically-pressed $\mathrm{Y}_{2} \mathrm{O}_{3}$-doped $-\mathrm{Si}_{3} \mathrm{~N}_{4}$, J. Eur. Ceram. Soc. 19 (1999) 227-237, http://dx.doi.org/10.1016/S0955-2219(98) 00184-8.

[4] J.R. Dryden, On the creep in ceramics due to a viscous grain boundary phase, J. Mech. Phys. Solids 48 (2000) 2115-2135.

[5] R.S. Kottada, A.H. Chokshi, The high temperature tensile and compressive deformation characteristics of magnesia doped alumina, Acta Mater. 48 (2000) 3905-3915.

[6] E. Blond, N. Schmitt, F. Hild, Ph. Blumenfeld, J. Poirier, Modelling of high temperature asymmetric creep behavior of ceramics, J. Eur. Ceram. Soc. 25 (2005) 1819-1827.

[7] S.I. Warshaw, F.H. Norton, Deformation behavior of polycrystalline aluminum oxide, J. Am. Ceram. Soc. 45 (1962) 479-486.

[8] H. Timoshenko, Non-stationary stress distribution in a ceramic bending beam during constant load, Res. Mech. 10 (1984) 55-71. 
[9] T.J. Chuang, Estimation of power-law creep parameters from bend test data, J. Mater. Sci. 21 (1986) 165-175.

[10] S.M. Wiederhorn, L. Chuck, E.R. Fuller Jr., N.J. Tighe, Creep rupture of siliconized silicon carbide, in: R.E. Tressler, G.L. Messing, C.G. Pantano, R.E. Newnhan (Eds.), Material Science Research, Tailoring Multiphase and Composite Ceramics, vol. 20, Plenum Press, New York, 1986, pp. 755-773.

[11] C.F. Chen, T.J. Chuang, Improved analysis for flexural creep with application to SiAlON ceramics, J. Am. Ceram. Soc. 73 (1990) 2366-2373.

[12] M.W. Bird, R.P. Aune, F. Yu, P.F. Becher, K.W. White, Creep behavior of a zirconium diboride-silicon carbide composite, J. Eur. Ceram. Soc. 33 (2013) 2407-2420, http://dx.doi.org/10.1016/j.jeurceramsoc.2013.03.022.

[13] G. Dusserre, F. Nazaret, L. Robert, T. Cutard, Applicability of image correlation techniques to characterise asymmetric refractory creep during bending tests, J. Eur. Ceram. Soc. 33 (2013) 221-231, http://dx.doi.org/10.1016/j. jeurceramsoc.2012.09.011.

[14] P. Leplay, O. Lafforgue, F. Hild, Analysis of asymmetrical creep of a ceramic at $1350^{\circ} \mathrm{C}$ by digital image correlation, J. Am. Ceram. Soc. 98 (2015) 2240-2247, http://dx.doi.org/10.1111/jace.13601.

[15] D.J. Lee, I. Palley, Tensile creep in ceramics using four-point bending test, J. Mech. Sci. Technol. 8 (1994) 325-331.

[16] D.J. Lee, Estimating tensile creep rate of ceramics from flexure data, J. Eur. Ceram. Soc. 16 (1996) 1377-1383.

[17] A.Y. Peras, The flexural creep of refractory materials, Refract. Ind. Ceram. 18 (1977) 294-297.

[18] P.K. Talty, R.A. Dirks, Determination of tensile and compressive creep behaviour of ceramic materials from bend tests, J. Mater. Sci. 13 (1978) 580-586.

[19] P. Leplay, J. Réthoré, S. Meille, M.-C. Baietto, Identification of asymmetric constitutive laws at high temperature based on Digital Image Correlation, J. Eur. Ceram. Soc. 32 (2012) 3949-3958, http://dx.doi.org/10.1016/j. jeurceramsoc.2012.03.024.

[20] P. Grassl, K. Lundgren, K. Gylltoft, Concrete in compression: a plasticity theory with a novel hardening law, Int. J. Solids Struct. 39 (2002) 5205-5223.

[21] D.C. Drucker, W. Prager, Soil mechanics and plastic analysis or limit design, Q. Appl. Math. 10 (1952) 157-165.

[22] D.C. Drucker, Concept of path independence and material stability for soils. Proc. IUTAM Symposium on Rheology and Soil Mechanics, Grenoble April, 1-8, Springer, Verlag Berlin, 1964, pp. 23-46, http://dx.doi.org/10.1007/9783-642-46047-0_3, 1966.

[23] J.-F. Jiang, Y.-F. Wu, Identification of material parameters for Drucker-Prager plasticity model for FRP confined circular concrete columns, Int. J. Solids Struct. 49 (2012) 445-456, http://dx.doi.org/10.1016/j.ijsolstr.2011.10.002.

[24] J. Jiang, Y. Wu, X. Zhao, Application of drucker-Prager plasticity model for stress-Strain modeling of FRP confined concrete columns, Procedia Eng. 14 (2011) 687-694.
[25] G. Arslan, Sensitivity study of the Drucker-Prager modeling parameters in the prediction of the nonlinear response of reinforced concrete structures, Mater. Des. 28 (2007) 2596-2603.

[26] O. Valentin, F. Nazaret, G. Dusserre, T. Cutard, Mechanical engineering creep simulation of ceramic materials with the Drucker-Prager model. 55th International Colloquium on Refractories, Aachen, Germany September, 2012, pp. 19-20.

[27] S. Jin, H. Harmuth, D. Gruber, R. Rössler, Influence of creep on the thermomechanical behavior of a rh-snorkel.Proc. of UNITECR, 14th Biennial Wolrdwide Congress on Refractories, Vienna Austria September 15-18, 2015.

[28] D.C. Drucker, Relation of experiments to mathematical theories of plasticity, J. Appl. Mech. 16 (1949) 349-359.

[29] I.Y. Tsvelodub, The Stability Postulate and Its Applications in Creep Theory of Metallic Materials, Institute of Hydrodynamics, Novosibirsk, 1991.

[30] P.A. Vermeer, R. de Borst, Non-associated plasticity for soils concrete and rock, HERON 29 (1984) 1-64.

[31] G.Z. Voyiadjis, A. Zolochevsky, Modeling of secondary creep behavior for anisotropic materials with different properties in tension and compression, Int. J. Plast. 14 (1998) 1059-1083, http://dx.doi.org/10.1016/S07496419(98) 00045-X.

[32] A. Zolochevsky, G.Z. Voyiadjis, Theory of creep deformation with kinematic hardening for materials with different properties in tension and compression, Int. J. Plast. 21 (2005) 435-462, http://dx.doi.org/10.1016/j.ijplas.2003.12.007.

[33] ASTM-E1876, Standard Test Method for Dynamic Young's Modulus, Shear Modulus, and Poisson's Ratio by Impulse Excitation of Vibration, ASTM, West Conshohocken, PA, 2009.

[34] H. Marzagui, T. Cutard, Characterisation of microstructural evolutions in refractory castables by in situ high temperature ESEM, J. Mater. Process. Technol. 155-156 (2004) 1474-1481, http://dx.doi.org/10.1016/j.jmatprotec. 2004.04.365.

[35] F. Nazaret, H. Marzagui, T. Cutard, Influence of the mechanical behaviour specificities of damaged refractory castables on the Young's modulus determination, J. Eur. Ceram. Soc. 26 (2006) 1429-1438, http://dx.doi.org/10. 1016/j.jeurceramsoc.2005.03.231.

[36] G. Dusserre, G. Bernhart, F.M. Schmidt, G. Dour, Evaluation of viscous and elastic parameters of a borosilicate glass above transition temperature using optical instrumented squeeze tests, J. Non Newton. Fluid Mech. 166 (2011) 1229-1238, http://dx.doi.org/10.1016/j.jnnfm.2011.08.001.

[37] S. Jin, H. Harmuth, D. Gruber, Compressive creep testing of refractories at elevated loads-Device, material law and evaluation techniques, J. Eur. Ceram. Soc. 34 (2014) 4037-4042, http://dx.doi.org/10.1016/j.jeurceramsoc.2014.05. 034. 